11 Kaplan JE, Osame M, Kubota H, Igata A, Nishitani H, Maeda Y, et al. The risk of development of HTLV-I-associated myelopathy/tropical spastic paraparesis among persons infected with HTLV-I. fournal of Acquired Immune Deficiency Syndromes 1990;3:1096-101.

12 Chen Y-C, Wang C-H, Su I-J, Hu C-Y, Chou M-J, Lee TH, et al. Infection of human T-cell leukaemia virus type 1 and development of human T-cell leukemia/ymphoma in patients with hematologic neoplasma: a possible linkage to blood transfusion. Blood 1989;74: neoplasm

13 Hall WW, Takahashi H, Shi Wei Zhu, Ijichi S. Human T cell leukaemia virus, type II (HTLV-II). In: Neu HC, Levey JA, Weiss RA, eds. Focus on HIV. Edinburgh: Churchill Livingstone, 1993

14 Hjelle B, Appenzeller O, Mills R, Alexander S, Torrez-Martinez N, Jahnke R, et al. Chronic neurodegenerative disease associated with HTLV-II infection. Lancet 1992;339:645-6.

15 Williams AE. HTLV II infection in US blood donors. Transfusion Today 1990;7:5.

16 Pillonel J, Courouce A-M, Brunet J-B, Lemaire J-M, Maniez M. Le depistage du HTLV dans les etablissments de transfusion Sanguine. La gazette de la Transfusion 1993;84:15-7.

17 Salker R, Tosswill JH, Barbara JAJ. HTLV-I/II antibodies in UK Blood donors. Lancet 1990;336:317.

18 Barbara J. Gelatin particle agglutination assay for HIV antibodies: a rapid, economical modification with increased sensitivity. Medical Laboratory Sciences 1989;46:135-40.

19 Fujino $R$, Kuwato $K$, Ikeda $M$, Miyakoshi $H$, Mizukoshi $M$, Imai J. Improvement of gelatin particle agglutination test for detection of antiHTLV-I antibody. Fapanese fournal of Cancer Research 1991;82:367-70.

20 Tuke PW, Luton P, Garson JA. Differential diagnosis of HTLV-I and HTLV-II infections by restriction enzyme analysis of "nested" PCR products. 7 Virol Meth 1992;40:163-74.

21 Erlich G, Greenberg S, Abbott M, eds. PCR protocols: a guide to methods and applications. Oxford: Academic Press, 1990

22 Kiyokawa T, Yamaguchi K, Nishimura Y, Fukuoka N, Watanabe T, Takatsuki K. Western blot criteria for HTLV-I. Lancet 1991;338:312

23 Couroucé A-M, Pillonel J, Lemaire J-M, Maniez M, Brunet J-B. Seroepidemiology of HTLV-I/II in universal screening of blood donations in France. AIDS 1993;7:841-7.

24 Meytes D, Schochat B, Lee H, Nadel G, Sidi Y, Cerney M. Serological and molecular survey for HTLV-I infection in a high-risk Middle Eastern group. Lancet 1990;336:1553-5.

25 McAlpine L, Parry JV, Tosswill JHC. An evaluation of an enzyme immunoassay for the combined detection of antibodies to HIV-1, HIV-2, HTLV-I and HTLV-II. AIDS 1992;6:387-91.

(Accepted 23 August 1993)

\title{
Twins, triplets, and cerebral palsy in births in Western Australia in the 1980s
}

\author{
Beverly Petterson, Karin B Nelson, Linda Watson, Fiona Stanley
}

\begin{abstract}
Objectives-To examine the rate of cerebral palsy in twins and triplets in births from 1980 to 1989 in Western Australia and to identify factors associated with increase in risk.

Design-Pluralities for all births in Western Australia were identified through the standardised midwives' notification system, and cases of cerebral palsy were identified from the Western Australian cerebral palsy register.
\end{abstract}

Main outcome measures-Multiple births, cerebral palsy, excluding postneonatal cause.

Results-The prevalence of cerebral palsy in triplets, of 28 per 1000 survivors to 1 year $(95 \%$ confidence interval 11 to 63 ) exceeded that in twins $(7 \cdot 3 ; 5.2$ to 10$)$ and singletons $(1.6 ; 1.4$ to 1.8$)$. Although twins and triplets were more likely than singletons to be low in birth weight, their risks of cerebral palsy if low in birth weight were similar. In contrast, in normal birthweight categories twins had a higher rate of cerebral palsy $(4 \cdot 2 ; 2 \cdot 2$ to $7 \cdot 7)$ than singletons $(1.1 ; 1.0$ to 1.3$)$. The prevalence of cerebral palsy was similar in twins of unlike sex pairs, all of whom are dizygotic, and in like sex pairs. A twin pair in which one member died in utero was at higher risk of cerebral palsy: 96 per 1000 twin pairs (36 to 218 ) compared with $12(8 \cdot 2$ to 17$)$ for twin pregnancies in which both survived. There was a similar but non-significant trend for death of one triplet to be associated with increased risk of cerebral palsy in the survivors of the set.

Conclusion-Triplet pregnancies produced a child with cerebral palsy 47 times more often than singleton pregnancies did and twin pregnancies eight times more often. Eighty six per cent of cerebral palsy in multiple births was in twins. As multiple births are increasing mainly because of personal and medical decisions the increased risk of cerebral palsy in multiple births is of concern.

\section{Introduction}

In Western Australia, as in the United Kingdom, ${ }^{12}$ the United States, ${ }^{34}$ and elsewhere, ${ }^{56}$ multiple births have increased in recent decades. Between 1980 and 1989 the proportion of twins in Western Australia rose from $1.9 \%$ to $2.9 \%$ and higher order multiple births from $0 \cdot 1 \%$ to $1 \cdot 0 \%$. $^{7}$ Concern has been expressed about the perinatal and longer term complications associated with these increases. ${ }^{124}$

Twins born in Western Australia in 1991 were four times more likely than singletons to be stillborn and five times more likely to die as neonates. ${ }^{7}$ Twins were 16 times more likely than singletons to weigh less than $1500 \mathrm{~g}$ at birth; one in 3.3 liveborn infants weighing under $1500 \mathrm{~g}$ was from a multiple birth. Twins required neonatal intensive care eight times more often than singletons, 21 times more often for longer than 28 days. Comparable figures for triplets are not available in Western Australia but probably the risks and stresses for triplet births are even greater. The problems experienced by parents and medical staff and the costs resulting from the increase in multiple births have been discussed in the lay $^{6}{ }^{8}$ and medical press. ${ }^{2910}$

In addition to their vulnerability to early illness and death, ${ }^{11}$ twins are at higher risk of developing cerebral palsy. ${ }^{1213}$ A previous population based report from Western Australia describing births from 1956 to 1985 observed a prevalence of cerebral palsy in twins 2.6 times that in singletons and found suggestive but, because of small numbers, inconclusive evidence that triplets were at higher risk of cerebral palsy than twins. ${ }^{14}$ We now update that earlier report and further examine the risk of cerebal palsy or of death in multiple births in this population in the decade of the 1980s.

\section{Methods}

Plurality and annual numbers of births and their characteristics including birth weight for the years 1980 to 1989 were obtained from the maternal and child health research database, which includes midwives' notifications of births (a statutory file of all births in the state collected by the health department of Western Australia including stillbirths of at least 20 weeks' gestation or $400 \mathrm{~g}$ birth weight), and linked to birth registrations and deaths to the age of 1 year provided by the registrar general of Western Australia. Population data for years before 1980 were obtained from publications of the Australian Bureau of Statistics $^{15}$ and the health department of Western Australia. ${ }^{16} 17$

Details of cases of cerebral palsy were obtained from the Western Australian cerebral palsy register, an ongoing population based system that uses multiple 
sources to detect affected children and has data on birth cohorts from 1956. This register is also held on the maternal and child health research database and can be linked to births and deaths to 1 year of age from 1980 onwards. Definitions and methods used for the register have been described previously. ${ }^{18}$ To correct for possible underdetection of cases of cerebral palsy in singleton births in 1988 and 1989, when we calculated the proportion of multiple births among cases of cerebral palsy over time, a correction factor based on the proportion of previous cohorts ascertained at 3 years $(64 \%)$ and 4 years $(91 \%)$ was used. This added four cases in singletons in 1988 and 14 cases in singletons in 1989.

Children with mild, moderate, or severe cerebral palsy, except those with a documented postneonatal cause, were included in the study. Unless indicated otherwise, prevalence of cerebral palsy was based on survivors to 1 year of age. This is different from earlier research in which rates were calculated per 1000 live births or neonatal survivors. ${ }^{14}{ }^{19}$ Information on like or unlike sex of twin pairs was the only surrogate (and imprecise) indicator available for zygosity.

Four children with cerebral palsy who were known through medical records or parental interview to have been twins and two triplets with an early fetal death of one member of the set had been classified on midwives' notifications as singletons or twins, respectively. Because there was no way to recognise such misidentification of plurality among children without cerebral

TABLE I-Numbers of singletons, triplets, and twins with selected outcomes in Western Australia, 1980-9. Plurality as recorded on midwives' notifications

\begin{tabular}{lrrr}
\hline Detail & Singletons & Twins & Triplets \\
\hline Total births & $228329^{\star}$ & 5288 & 237 \\
Live births & 226517 & 5132 & 225 \\
Pairs/sets & & 2644 & 79 \\
Stillbirths & 1696 & 156 & 12 \\
Deaths: & 1086 & 188 & 9 \\
$\quad$ Neonatal & 744 & 29 & 1 \\
$\quad$ Postneonatal & 224687 & 4915 & 215 \\
Survivors at 1 year & 362 & 38 & 6 \\
Children with cerebral palsy: & 358 & 36 & 6 \\
$\quad$ Among live births & & & \\
\hline
\end{tabular}

${ }^{\star}$ Includes 116 births of unknown outcome.

TABLE II-Prevalences (95\% confidence intervals) of deaths (stillbirth, neonatal, postneonatal), cerebral palsy, or either in Western Australia, 1980-9. Plurality as recorded on midwives' notifications

\begin{tabular}{|c|c|c|c|}
\hline Category* & Singleton & Twin & Triplet \\
\hline \multicolumn{4}{|c|}{ Deaths (stillbirth, neonatal, postneonatal): } \\
\hline Per 1000 births & $15 \cdot 6(15$ to 16$)$ & $70 \cdot 5(64$ to 78$)$ & 92.8 (60 to 139$)$ \\
\hline Per 1000 pregnancies & $15 \cdot 6(15$ to 16$)$ & $93.8(83$ to 106$)$ & $152(84$ to 254$)$ \\
\hline \multicolumn{4}{|l|}{ Cerebral palsy: } \\
\hline Per 1000 live births & $1.6(1.4$ to 1.8$)$ & $7 \cdot 4(5 \cdot 3$ to 10$)$ & $26.7(11$ to 60$)$ \\
\hline Per 10001 year survivors & $1.6(1.4$ to 1.8$)$ & $7 \cdot 3(5 \cdot 2$ to 10$)$ & $27.9(11$ to 63$)$ \\
\hline Per 1000 pregnancies & $1.6(1.4$ to 1.8$)$ & $13 \cdot 2(9 \cdot 4$ to 19$)$ & 75.9 (31 to 164$)$ \\
\hline \multicolumn{4}{|l|}{ Death or cerebral palsy: } \\
\hline Per 1000 births & $17 \cdot 1(16 \cdot 6$ to $17 \cdot 1)$ & $77 \cdot 3$ (70 to 85$)$ & $118(81$ to 168$)$ \\
\hline Per 1000 pregnancies & $17 \cdot 1(16 \cdot 6$ to $17 \cdot 1)$ & $103(92$ to 116$)$ & 190 (114 to 297$)$ \\
\hline
\end{tabular}

^Four singletons and two twins with severe cerebral palsy who died before age of 1 year are counted in deaths and in cerebral palsy among live births, but are not counted in cerebral palsy in survivors nor double counted for death or cerebral palsy.

TABLE III-Total numbers of singleton twin and triplet pregnancies and rates of twin and triplet gestations per 1000 pregnancies in Western Australia, 1960-89

\begin{tabular}{lcccc}
\hline & \multicolumn{2}{c}{ Pregnancies $^{\star}$} & & \\
\cline { 2 - 2 } Years & Total/twin/triplet & & Twinning rate† & Triplet rateł \\
\hline $1960-4$ & $84238 / 825 / 5$ & $9 \cdot 8$ & $0 \cdot 059$ \\
$1965-9$ & $90592 / 960 / 7$ & $10 \cdot 6$ & $0 \cdot 077$ \\
$1970-4$ & $107757 / 1028 / 9$ & $9 \cdot 5$ & $0 \cdot 084$ \\
$1975-9$ & $101772 / 970 / 9$ & $9 \cdot 5$ & $0 \cdot 088$ \\
$1980-4$ & $110345 / 1153 / 20$ & $10 \cdot 4$ & $0 \cdot 181$ \\
$1985-9$ & $120713 / 1491 / 59$ & $12 \cdot 4$ & $0 \cdot 489$ \\
\hline
\end{tabular}

*Pregnancy counted if at least one child survived to 20 weeks' gestation or had birth weight of at least $400 \mathrm{~g}$

$t x_{1}^{2}$ for linear trend $=26 \cdot 6, p<0.0001$.

$\mp \chi_{1}^{2}$ for linear trend $=63 \cdot 0, p<0.0001$. palsy (the denominator group) these retrospectively ascertained cases were counted according to the plurality indicated on the midwives' notifications of birth. This report differs from an earlier paper from this data set in this regard. ${ }^{14}$

Rates calculated per 1000 pregnancies relate to pregnancies in which at least one child survived to 20 weeks' gestation or had a birth weight of at least $400 \mathrm{~g}$. Prevalence estimates are presented with $95 \%$ confidence intervals, ${ }^{20}$ as are odds ratios..$^{21}$ Analyses for linear trends and for odds ratios adjusted for important confounders were based on standard unconditional logistic regression..$^{22}$

\section{Results}

Between the beginning of 1980 and the end of 1989 , 226517 singletons, 5132 twins, and 225 triplets were born alive in Western Australia (table I). Of these, 38 twins and six triplets were found to have cerebral palsy. Three pairs of twins were concordant for cerebral palsy.

In all triplets and in $28(78 \%)$ affected twins the form of cerebral palsy was spastic diplegia or hemiplegia, or a combination of these spastic conditions. Rates per 1000 live births for hemiplegia and diplegia were several times higher in multiple than in singleton births (hemiplegia 2.98 in multiples, 0.47 in singletons; diplegia 3.35 in multiples, 0.46 in singletons). Adjusted for birth weights of $<1500 \mathrm{~g}, 1500-2499 \mathrm{~g}$, and $\geqslant 2500 \mathrm{~g}$ the odds ratios for multiples compared with singletons were $1 \cdot 8(1.0$ to 3.2$)$ and $1 \cdot 1(0.7$ to 1.9$)$, respectively. No differences were noted between children of singleton and multiple births in the severity of their cerebral palsy or in the occurrence or severity of associated intellectual disability.

Details of all twins and triplets with cerebral palsy and their cotwins and cotriplets, including birth weight, birth order, sex, and outcome from the Western Australian cerebral palsy register, are listed in the appendix (tables AI and AII).

PREVALENCE OF CEREBRAL PALSY OR DEATH BY PLURALITY

Twin infants were about four and a half times more likely than singletons to die before their first birthdays (table II). Early mortality in triplets tended to be higher than in twins, but the confidence intervals around these values for triplets were wide and overlapped those for twins.

The rate of cerebral palsy, whether considered in live births or in survivors to 1 year, was 4.6 times higher in twins than singletons and higher still in triplets than in twins. Triplets had an observed rate of cerebral palsy about 17 times higher than the rate in singletons. Triplet pregnancies produced a child with cerebral palsy 47 times more often than singleton pregnancies. Despite the striking increases in risks for triplets, triplet gestations were uncommon and twins accounted for $86 \%$ of the cerebral palsy among multiple births.

MULTIPLE BIRTHS AMONG CASES OF CEREBRAL PALSY BY YEAR

The proportion of multiple gestations in Western Australia has increased considerably between 1960 and 1989 (table III). The average five yearly increase was $3.9 \%(2.4$ to 5.4$)$ in twins and $67 \%(45$ to 93$)$ for triplets. This has contributed to a significant annual increase in the proportion of multiple births associated with cases of cerebral palsy of $3.0 \%(0.5$ to 5.6$)$ over the same time period ( $\chi^{2}$ for linear trend $=5 \cdot 45, p=0.02$ ). Before $1970,5 \cdot 3 \%$ of all cerebral palsy was in multiple births; from then to 1980 it was $6 \cdot 6 \%$ and rose to $10 \cdot 3 \%$ in the decade up to 1990 . 
PREVALENCE OF CEREBRAL PALSY BY BIRTH ORDER AND SEX

In non-concordant pairs of twins the twin with cerebral palsy was the firstborn in 15 pairs and the secondborn in 17. Of pairs concordant for cerebral palsy one was unlike in sex and two were of like sex. The prevalence of cerebral palsy in boys tended to exceed that in girls: for twins the rate in boys was 8.5 per 1000 at the age of 1 year (5.4 to 13$)$ and in girls $5 \cdot 3$ ( 3.6 to 10$)$, but the differences were not significant. In twins of like sex pairs the rate of cerebral palsy was not significantly higher in boy-boy $(14 \cdot 6 ; 8 \cdot 1$ to 26$)$ than in girl-girl pairs $(6 \cdot 9 ; 2 \cdot 8$ to 16$)$. Four of six triplets with cerebral palsy were boys. The observed prevalence of cerebral palsy in twins of unlike sex $(15.9 ; 8.6$ to 28$)$ was not significantly different from that in those of like $\operatorname{sex}(11 \cdot 9 ; 7 \cdot 6$ to 19$)$.

\section{PREVALENCE OF CEREBRAL PALSY BY BIRTH WEIGHT}

The mean (SE) birth weight in liveborn singletons was $3377(1 \cdot 14) \mathrm{g}$, in twins $2431(8 \cdot 8) \mathrm{g}$, and in triplets $1761(38 \cdot 1) \mathrm{g}$. The distribution of birth weight was lower with increasing plurality (figure). Forty six per cent of surviving twins and $90 \%$ of surviving triplets to the age of 1 year were low $(<2500 \mathrm{~g})$ in birth weight compared with $4 \cdot 4 \%$ of singletons (table IV).

The prevalence of cerebral palsy was higher in babies of low birth weight in all pluralities. Thirty five per cent of cases of cerebral palsy in singletons, $69 \%$ in twins, and all cases in triplets were in infants born weighing less than $2500 \mathrm{~g}$. Although twins were 10 times more likely than singletons to be low in birth weight, with an excess even greater in triplets, the

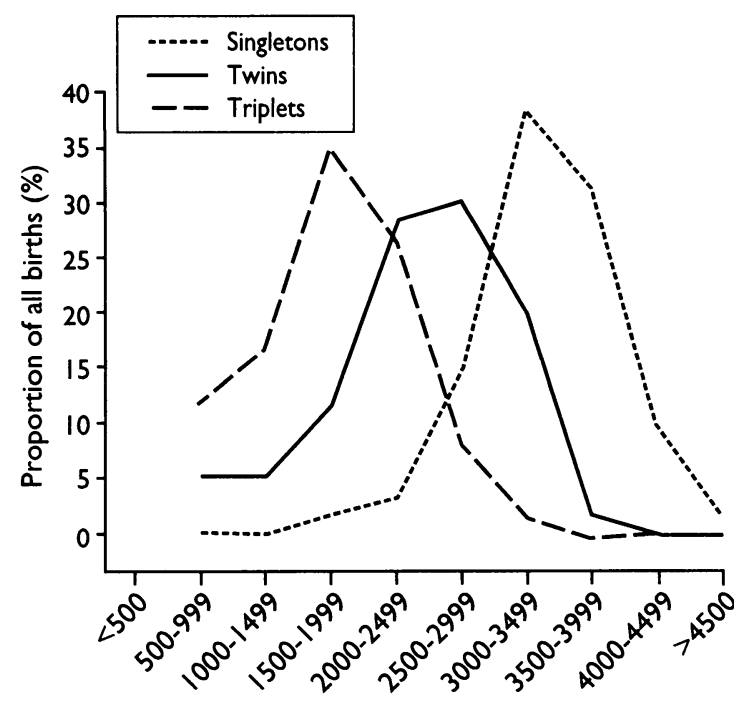

Birth weight (g)

Distribution of birth weights of liveborn singletons, twins, and triplets in Western Australia, 1980-9.

TABLE IV-Prevalences of cerebral palsy per 1000 survivors to 1 year in singletons, twins, and triplets by birth weight in Western Australia, 1980-9

\begin{tabular}{|c|c|c|c|}
\hline \multirow[b]{2}{*}{ Detail } & \multicolumn{3}{|c|}{ Birth weight (g) } \\
\hline & $<1500$ & $1500-2499$ & $\geqslant 2500$ \\
\hline \multicolumn{4}{|c|}{ Singletons } \\
\hline No born & 1147 & 8688 & 214918 \\
\hline No with cerebral palsy & 59 & 66 & 233 \\
\hline Prevalence of cerebral palsy ( $95 \%$ confidence interval) & $51 \cdot 4(40$ to 66$)$ & $7 \cdot 6(5 \cdot 9$ to $9 \cdot 7)$ & $1.1(0.95$ to 1.2$)$ \\
\hline \multicolumn{4}{|c|}{ Twins } \\
\hline No born & 248 & 2031 & 2636 \\
\hline No with cerebral palsy & 9 & 16 & 11 \\
\hline Prevalence of cerebral palsy ( $95 \%$ confidence interval) & $36 \cdot 3(18$ to 70$)$ & $7 \cdot 9(4 \cdot 7$ to 13$)$ & $4 \cdot 2(2 \cdot 2$ to $7 \cdot 7)$ \\
\hline \multicolumn{4}{|c|}{ Triplets } \\
\hline No born & 55 & 139 & 21 \\
\hline No with cerebral palsy & 4 & 2 & 0 \\
\hline Prevalence of cerebral palsy ( $95 \%$ confidence interval) & $72 \cdot 7(24$ to 184$)$ & $14.4(2.5$ to 56$)$ & \\
\hline
\end{tabular}

TABLE v-Prevalences of cerebral palsy by fate of cotwin or cotriplet per 1000 survivors to 1 year or per 1000 pregnancies of which at least one child survived to 1 year in Western Australia, 1980-9

\begin{tabular}{|c|c|c|}
\hline Plurality & No with cerebral palsy & $\begin{array}{l}\text { Prevalence ( } 95 \% \\
\text { confidence interval) }\end{array}$ \\
\hline \multicolumn{3}{|c|}{ Fetal death ${ }^{\star}$} \\
\hline Twin pairs & $5 / 52$ & $96 \cdot 2$ (36 to 218 ) \\
\hline \multicolumn{3}{|l|}{ Triplets: } \\
\hline Per child & $2 / 13$ & 154 (27 to 463$)$ \\
\hline Per 1000 pregnancies & $2 / 7$ & 286 (51 to 697$)$ \\
\hline \multicolumn{3}{|c|}{ Both/all liveborn $\dagger$} \\
\hline \multicolumn{3}{|l|}{ Twin pairs: } \\
\hline Per child & $31 / 4844$ & $6 \cdot 4(4.4$ to $9 \cdot 2)$ \\
\hline Per 1000 pregnancies & $30 / 2530$ & $11.9(8.2$ to 17$)$ \\
\hline \multicolumn{3}{|l|}{ Triplets: } \\
\hline Per child & $4 / 138$ & $29.0(9 \cdot 3$ to 77$)$ \\
\hline Per 1000 pregnancies & $4 / 70$ & $57 \cdot 1(19$ to 147$)$ \\
\hline
\end{tabular}

${ }^{\star}$ Base number is number of pairs or triplet sets in which at least one child was born alive and one died in utero.

tBase number is pairs or sets in which all members were born alive.

observed rate of cerebral palsy in infants of low or very low birth weight was not different from that in singletons of the same weight group (table IV). In twins born weighing $2500 \mathrm{~g}$ or more, however, the observed rate of cerebral palsy was 3.8 times higher than in singletons of that weight group. Thus, although multiple births were greatly overrepresented among low and very low birthweight groups, the risk of cerebral palsy in twins did not exceed that of singletons of similar weight except in infants of $2500 \mathrm{~g}$ or more.

In non-concordant twins the affected twin was the heavier of the pair in 20 cases, the lighter in nine, and the same in one. In twins in which the weight differed by $500 \mathrm{~g}$ or more the affected twin was the heavier in five and the lighter in three. In five of the six sets of triplets the child with cerebral palsy was the heaviest member of the set.

RISK BY DEATH OF ONE OR MORE FETUSES IN PAIR OR SET

In 52 twin pregnancies one member of the pair was born alive while the other died in utero (table V). In twins who survived to 1 year after the death of a cotwin the prevalence of cerebral palsy was $96 \cdot 2$ per 1000,15 times higher than for twins who were both live born, in whom the prevalence was $6 \cdot 4$, and 60 times higher than for liveborn singletons, in whom the prevalence was $1 \cdot 6$.

Of the 79 sets of triplets in this population there were seven in which at least one child survived to 1 year while another died in utero. The observed prevalence of cerebral palsy in triplets with a cotriplet who died as a fetus was 154 per 1000 survivors to 1 year, while comparable figures for triplet sets of which all members were born alive were 29.0 per child and $57 \cdot 1$ per set. With such small numbers of triplets these differences, although dramatic, were not significant.

\section{Discussion}

Experience in Western Australia in the 1980s indicates that multiple births are at increased risk of cerebral palsy. The risks of producing a child with cerebral palsy were $0.2 \%, 1.3 \%$, and $7.6 \%$ for singleton, twin, and triplet pregnancies, respectively. Furthermore, pregnancies in which intrauterine death of a cotwin or cotriplet occurred were associated with even greater risks of cerebral palsy: $10 \%$ in twins and $29 \%$ in triplets.

The only other source of population based information on long term neurological morbidity in triplets of which we are aware is the survey of Botting $e t$ al. ${ }^{9}$ This survey included triplet and higher order multiple births in the United Kingdom but was limited to multiple gestations in which three or more infants survived the neonatal period. Hence it probably 
underestimated neurological morbidity because it excluded children at special risk by virtue of fetal death of a cotriplet. Their study observed a prevalence of cerebral palsy of 17.4 per 1000 triplet or higher order multiple births and among those born weighing less than $1500 \mathrm{~g}$ a prevalence of 68 per 1000 , values reasonably comparable with those reported here despite the differences in methods.

\section{COMPARISON WITH OTHER STUDIES}

Our results agree in several respects with those from a recent population based study on cerebral palsy from California. ${ }^{13}$ Twins are much more likely than singletons to be low in birth weight, but at a given low birth weight the risk of cerebral palsy in twins does not differ from that in singletons of similar low weight. In twins of $2500 \mathrm{~g}$ or more the risk is considerably higher than in singletons. Death of one of a pair of twins is associated with a sharply increased risk of cerebral palsy in the survivor (also reported in a Swedish study. ${ }^{23}$ ). The risk of cerebral palsy is similar in twins of unlike and like sex pairs. Multiple births contributed a larger proportion of the total number of cases of cerebral palsy in the 1980 s than in the past.

The higher rate of cerebral palsy in multiple births is probably mostly explained by their tendency to be of low birth weight. There may, however, be additional adverse effects of "twinning" as the risk of cerebral palsy in twins whose birth weight was $2500 \mathrm{~g}$ or more was higher than in singletons of the same weight. This was seen in the Californian twin study ${ }^{13}$ and has also been shown for mortality. ${ }^{112426}$ Thus the possibility arises that as twin pregnancies approach term, the chances of perinatal death or disability exceed those in twins of lower birth weight.

\section{CARE IN MULTIPLE PREGNANCY}

Multiple gestations are one of the few kinds of pregnancies identifiable fairly early as being at high risk of cerebral palsy, and they are also at risk of antenatal and neonatal mortality. Such pregnancies may therefore warrant further investigation including antenatal fetal monitoring as term approaches, high resolution cranial ultrasound examination of the infants soon after birth, and follow up to evaluate neurological outcome in an effort to identify factors contributing to their fairly high risk of brain disease.

Fetal deaths early in pregnancy are likely to be underascertained in studies in which plurality is identified from vital statistics records, and this was noted in both our study and a comparable California investigation. ${ }^{13}$ Other study designs incorporating ultrasonography early in gestation and information on follow up will be necessary to examine more fully the

\section{Clinical implications}

- Rates of cerebral palsy are higher in triplets than in twins, who have higher rates than singletons

- Much but not all of the increased risk of cerebral palsy is related to the tendency of twins and triplets to be of low birth weight

- Rates of multiple births are rising because of increased use of treatments for infertility and a rise in births to older women

- In this study if one or more fetus of a multiple birth died in utero the risk of cerebral palsy was much higher in the surviving fetuses than if all survived

- The proportion of all cases of cerebral palsy occurring in multiple births is rising association of in utero death with neurological disability in survivors of multiple gestations.

\section{TRENDS IN MULTIPLE BIRTHS}

Multiple births are more common now than in past years. While factors such as more births to older women may play a part in this trend, ${ }^{13}$ treatment of infertility is probably the major contributor to this increase. ${ }^{27}$ Survival of low weight twins and triplets has also increased over recent decades as it has for singletons of low birth weight. Since both demographic shifts and most forms of assisted fertility produce an increase chiefly in dizygotic births, it is noteworthy that twin pairs of unlike sex, who are all dizygotic, are not at lower risk of cerebral palsy than like sex pairs. This finding agrees with those from another recent study. ${ }^{13}$

Our findings should be confirmed and extended to other population based contemporary data sets that monitor long term neurological outcome and are able to incorporate information on prenatal and perinatal events. Unfortunately, few such data sets exist. Our report shows that using an established register of cerebral palsy allows rapid assessment of the impact of societal changes and changes in medical management on the occurrence of an important form of long term neurological morbidity.

\section{CONCLUSIONS}

Cerebral palsy is, except in its mildest forms, a disabling and costly condition often accompanied by other neurological disabilities. The likelihood per pregnancy of long term neurological morbidity, which is eight times greater for twin pregnancies than for singletons and 47 times greater for triplet pregnancies, is relevant for obstetricians and for prospective parents as they make decisions concerning options for the treatment of infertility. Prospective parents considering modes of conception that increase the likelihood of multiple gestations need counselling that includes information on the full range of risks, including that of cerebral palsy, associated with multiple births. For parents, clinicians, and society who must often share the responsibility for disabled children, documentation of an increased risk of cerebral palsy in multiple births gives grounds for concern.

1 Botting BJ, Davies IM, Macfarlane AJ. Recent trends in the incidence of multiple births and associated mortality. Arch Dis Child 1987;62:941-50.

2 Levene MI, Wild J, Steer P. Higher multiple births and the modern management of infertility in Britain. Br f Obstet Gynaecol 1992;99:607-13.

3 Taffel SM. Health and demographic characteristics of twin births: United States, 1988. National Center for Health Statistics. Vital Health Stat 1992;21(50):1-15.

4 Kiely JL, Kleinman JC, Kiely M. Triplets and higher-order multiple births: time trends and infant mortality. Am $\mathcal{F}$ Dis Child 1992;146:862-8.

5 Mordel N, Ezra Y, Dorembus D, Benshushan A, Schenker JG, Sadovsky E. Triplets are not so rare any more. F Perinat Med 1992;20:117-22.

6 Rosenthal E. Cost of high-tech fertility: too many tiny babies. New York Times 1992 May 26;Sec C:1.

7 Gee V. Perinatal statistics in Western Australia. Ninth annual report of the Western Australian midwives notification system 1991. Perth: Health Department of Western Australia, 1992.

8 McKimmie M. Alarm over small baby boom. The West Australian 1993; February 17:15.

9 Botting BJ, Macfarlane AJ, Price FV. Three, four and more. A study of triplet and higher order births. London: HMSO, 1990.

10 Levene MI. Assisted reproduction and its implications for paediatrics. Arch Dis Child 1991;66:1-3.

11 Kiely JL. The epidemiology of perinatal mortality in multiple births. Bull N Y Acad Med 1990;66:618-37.

12 Scheller JM, Nelson KB. Twinning and neurologic morbidity. Am 7 Dis Child 1992;146:1110-3.

13 Grether JK, Nelson KB, Cummins SK. Twinning and cerebral palsy: experience in four northern California countries, births 1983 through 1985 Pediatrics (in press).

14 Petterson B, Stanley F, Henderson D. Cerebral palsy in multiple births in Western Australia: genetic aspects. Am $\mathcal{F}$ Med Genet 1990;37:346-51.

15 Barlett WM. Statistics of Western Australia. Demography 1969-demography 1979. Perth: Australian Bureau of Statistics, Western Australian Office, 1972-1981. (Catalogue No 3101.5.)

16 Stanley FJ, Hobbs MST. Perinatal mortality in Western Australia 1968-75. Perth, Western Australia: Public Health Department, 1979.

17 Stanley FJ, Hartfield MJ. Livebirths and perinatal mortality in Western Australia 1976-78. Perth, Western Australia: Department of Health and Medical Services, 1980 
18 Stanley FJ, Watson L. Methodology of a cerebral palsy register. The Western Australian experience. Neuroepidemiology 1985;4:146-60.

19 Stanley FJ, Watson L. Trends in perinatal mortality and cerebral palsy in Western Australia, 1967 to 1985. BM7 1992;304:1658-63.

20 Fleiss JL. Statistical methods for rates and proportions. 2nd ed. New York: Wiley, 1980:14.

21 Kleinbaum DG, Kupper LL, Morgenstern H. Epidemiologic research: principles and quantitative methods. Belmont, California: Lifetime Learning

22 Breslow NE, Day NE. Statistical methods in cancer research. Vol 1: The analysis of case-control studies. Lyon: IARC, 1980. (Scientific publications No 32.)

23 Rydhstrom H, Ingemarsson I. Prognosis and long-term follow-up of a twin after antenatal death of the co-twin. $¥$ Reprod Med 1993;38:142-6.
24 Buekens $P$, Wilcox $A$. Why do small twins have a lower mortality than small singletons? Am f Obstet Gynecol 1993;168:937-41.

25 McCarthy BJ, Sachs BP, Layde PM, Burton A, Terry JS, Rochat R. The epidemiology of neonatal death in twins. Am $\mathcal{f}$ Obstet Gynecol 1981;141: 252-6.

26 Spellacy WN, Handler A, Ferre CD. A case-control study of 1253 twin pregnancies from a 1982-1987 perinatal data base. Obstet Gynecol 1990;75: 168-71.

27 Webb S, Moore D, Stanley F. Increasing prevalence of multiple confinements in Western Australia and the impact of in-vitro fertilization [letter]. Med f Aust 1987;147:151-2

(Accepted 26 August 1993)

\section{Appendix}

TABLE AI-Cerebral palsy in twins, Western Australia births 1980-9, ordered by birth weight of affected child

\begin{tabular}{|c|c|c|c|c|c|c|c|c|c|c|}
\hline \multirow{2}{*}{$\begin{array}{l}\text { Case } \\
\text { No }\end{array}$} & \multirow{2}{*}{$\begin{array}{c}\text { Birth } \\
\text { weight }(\mathrm{g}) \\
\text { of case }\end{array}$} & \multirow{2}{*}{$\begin{array}{l}\text { Birth } \\
\text { order }\end{array}$} & \multirow{2}{*}{$\begin{array}{c}\text { Birth } \\
\text { weight }(g) \\
\text { of cotwin }\end{array}$} & \multicolumn{2}{|c|}{ Sex } & \multirow{2}{*}{$\begin{array}{l}\text { Outcome in } \\
\text { cotwin }\end{array}$} & \multirow{2}{*}{$\begin{array}{l}\text { Retrospective } \\
\text { ascertainment of } \\
\text { plurality }\end{array}$} & \multirow{2}{*}{$\begin{array}{c}\text { Year of } \\
\text { birth }\end{array}$} & \multirow[b]{2}{*}{ Motor handicap } & \multirow{2}{*}{$\begin{array}{l}\text { Motor } \\
\text { severity }\end{array}$} \\
\hline & & & & Case & Cotwin & & & & & \\
\hline $1^{\star}$ & 740 & 2 & 755 & $M$ & F & Neonatal death & Triplet & 1985 & Quadriplegia/dystonia & Severe \\
\hline $2 \dagger$ & 845 & 1 & 770 & M & $\mathbf{F}$ & & & 1983 & Right hemiplegia & Minimal \\
\hline $3 \ddagger$ & 980 & 1 & - & $M$ & - & Disappeared & Twin & 1988 & Right hemiplegia & Mild \\
\hline $4 \dagger$ & 1000 & 1 & 1250 & $\mathrm{~F}$ & $\mathbf{F}$ & Live born & & 1988 & Right hemiplegia & Minimal \\
\hline $5 t$ & 1120 & 1 & 410 & $M$ & $\mathbf{M}$ & Stillborn & & 1989 & Right hemiplegia & Minimal \\
\hline 6 & 1170 & 1 & 615 & $\mathrm{~F}$ & $M$ & Died $<1$ year & & 1989 & Right hemiplegia & Moderate \\
\hline 7 & 1185 & 2 & - & $M$ & $\mathrm{~F}$ & Stillborn (macerated) & & 1983 & Left hemiplegia & Mild \\
\hline $8^{\star}$ & 1250 & 2 & 795 & $\mathrm{~F}$ & $\mathrm{~F}$ & Neonatal death & Triplet & 1987 & Left hemiplegia & Moderate \\
\hline 98 & 1260 & 2 & 1085 & $M$ & $M$ & & & 1982 & Quadriplegia & Severe \\
\hline $10^{\circ}$ & 1340 & 1 & 790 & $\mathrm{~F}$ & F & Stillborn & & 1983 & Quadriplegia & Severe \\
\hline 11 & 1370 & 1 & 1485 & $\mathrm{~F}$ & $\mathbf{M}$ & & & 1987 & Diplegia right $>$ left & Moderate \\
\hline $12 \|$ & 1445 & 1 & 1570 & $M$ & $M$ & Cerebral palsy & & 1983 & Diplegia/athetosis & Severe \\
\hline $13 \|$ & 1455 & 1 & 1465 & $\mathbf{M}$ & $\mathrm{F}$ & Cerebral palsy & & 1987 & Diplegia & Severe \\
\hline $14 \|$ & 1465 & 2 & 1455 & $\mathrm{~F}$ & $\mathbf{M}$ & Cerebral palsy & & 1987 & Diplegia left > right & Moderate \\
\hline 15 & 1530 & 2 & 1155 & $M$ & $\mathbf{M}$ & Neonatal death & & 1981 & Diplegia & Moderate \\
\hline $16 \|$ & 1570 & 2 & 1455 & M & $\mathbf{M}$ & Cerebral palsy & & 1983 & Diplegia right $>$ left & Severe \\
\hline 17 & 1670 & 1 & 1705 & $M$ & $\mathrm{~F}$ & & & 1986 & Right hemiplegia & Mild \\
\hline 18 & 1700 & 1 & 1410 & $\mathrm{~N}$ & $\mathbf{N}$ & & & 1986 & Diplegia & Mild \\
\hline 19 & 1830 & 2 & 1815 & $\mathbf{M}$ & $M$ & & & 1988 & Diplegia & Severe \\
\hline 20 & 1865 & 2 & 880 & $\mathbf{M}$ & $\mathbf{F}$ & & & 1986 & Diplegia & Moderate \\
\hline $21 \ddagger$ & 1940 & 2 & - & M & - & $\begin{array}{l}\text { Termination of } \\
\text { pregnancy (case } \\
\text { survived) }\end{array}$ & Twin & 1989 & Diplegia & Moderate \\
\hline 22 & 1945 & 1 & 1420 & $M$ & $\mathbf{M}$ & & & 1989 & Diplegia & Moderate \\
\hline 23 & 1995 & 2 & 3025 & $\mathbf{M}$ & $\mathbf{M}$ & Beckwith syndrome & & 1987 & Diplegia left $>$ right & Moderate \\
\hline 24 & 2065 & 1 & 814 & $M$ & $M$ & Stillborn (macerated) & & 1980 & Quadriplegia/dystonia & Severe \\
\hline 25 & 1805 & 2 & 2100 & $\mathbf{M}$ & $\mathbf{M}$ & & & 1989 & Diplegia right $>$ left & Severe \\
\hline 26 & 2130 & 2 & 2260 & $\mathbf{M}$ & M & Cerebral palsy & & 1980 & Diplegia & Moderate \\
\hline $27 \dagger$ & 2135 & 2 & 1795 & $M$ & $\mathrm{~F}$ & & & 1986 & Left hemiplegia & Minimal \\
\hline $28 \|$ & 2260 & 1 & 2130 & $M$ & M & Cerebral palsy & & 1980 & Diplegia & Moderate \\
\hline 29 & 2295 & 1 & 3360 & $\mathrm{~F}$ & M & & & 1989 & Athetosis/diplegia & Moderate \\
\hline 30 & 2310 & 1 & 2770 & M & $\mathrm{F}$ & & & 1981 & $\begin{array}{l}\text { Right hemiplegia/ } \\
\text { dystonia }\end{array}$ & Mild \\
\hline 31 & 2370 & 1 & 2770 & $\mathrm{~F}$ & $\mathbf{F}$ & & & 1988 & Diplegia/dystonia & Moderate \\
\hline 32 & 2380 & 1 & 1990 & $\mathbf{M}$ & $M$ & Stillborn & & 1989 & Diplegia right $>$ left & Moderate \\
\hline 33 & 2610 & 2 & 2220 & $\mathrm{~F}$ & $\mathrm{~F}$ & & & 1983 & Diplegia left $>$ right & Moderate \\
\hline 34 & 2620 & 2 & 2530 & $\mathbf{F}$ & $\mathrm{F}$ & & & 1988 & Left hemiplegia & Moderate \\
\hline $35 \ddagger$ & 2645 & 2 & - & $\mathrm{F}$ & - & Spontaneous abortion & Twin & 1989 & Quadriplegia/dystonia & Severe \\
\hline 36 & 2655 & 2 & 2535 & $\mathbf{M}$ & $M$ & & & 1984 & Right hemiplegia & Mild \\
\hline 37 & 2680 & 2 & 3040 & M & $M$ & & & 1981 & Ataxia & Severe \\
\hline 380 & 2740 & 2 & 2460 & $\mathbf{F}$ & $\mathbf{M}$ & & & 1989 & Quadriplegia & Severe \\
\hline $39^{\circ}$ & 2755 & 2 & 2390 & $\mathbf{M}$ & $M$ & & & 1984 & Dystonia/athetosis & Severe \\
\hline 40 & 2810 & 2 & 2610 & $M$ & $\mathrm{~F}$ & & & 1981 & Right hemiplegia & Moderate \\
\hline 41 & 2890 & 2 & 2900 & $\mathrm{~F}$ & $\mathbf{F}$ & & & 1988 & Right hemiplegia & Moderate \\
\hline 42 & 3130 & 2 & 3570 & $M$ & F & & & 1987 & Left hemiplegia & Mild \\
\hline 43 & 3190 & 1 & 2590 & $\mathrm{~F}$ & $\mathrm{~F}$ & Stillborn & & 1987 & Quadriplegia & Severe \\
\hline 44 & 3265 & 1 & 2800 & $\mathrm{~F}$ & $M$ & & & 1985 & Left hemiplegia & Mild \\
\hline 45 & 3415 & 1 & 3060 & F & $\mathrm{F}$ & & & 1987 & Ataxia & Mild \\
\hline $46 \ddagger$ & 4035 & 1 & - & $\mathrm{F}$ & - & Stillborn (macerated) & Twin & 1983 & Dystonia/diplegia & Severe \\
\hline
\end{tabular}

*Classified as twin on midwives' notification, therefore included as twin rather than triplet as no comparable information in denominator tMinimal cerebral palsy excluded from study.

$\ddagger$ Classified as singleton on midwives' notification, therefore included as singleton rather than twin as no comparable information in denominator. Cerebral palsy death $<1$ year; excluded from study.

|Twin pairs concordant for cerebral palsy.

TABLE AII-Cerebral palsy in triplets, Western Australia births 1980-9, ordered by birth weight of affected child

\begin{tabular}{|c|c|c|c|c|c|c|c|c|c|c|c|c|c|c|}
\hline \multirow[b]{2}{*}{ Case } & \multirow[b]{2}{*}{$\begin{array}{l}\text { Year of } \\
\text { birth }\end{array}$} & \multirow[b]{2}{*}{$\begin{array}{l}\text { Birth } \\
\text { weight } \\
\text { (g) }\end{array}$} & \multirow[b]{2}{*}{$\begin{array}{l}\text { Case } \\
\text { order }\end{array}$} & \multirow[b]{2}{*}{ Sex } & \multirow[b]{2}{*}{ Motor handicap } & \multirow[b]{2}{*}{$\begin{array}{c}\text { Motor } \\
\text { severity }\end{array}$} & \multicolumn{4}{|c|}{ Cotriplet A } & \multicolumn{4}{|c|}{ Cotriplet B } \\
\hline & & & & & & & $\begin{array}{l}\text { Birth } \\
\text { weight } \\
\text { (g) }\end{array}$ & Order & Sex & Fate & $\begin{array}{l}\text { Birth } \\
\text { weight } \\
\text { (g) }\end{array}$ & Order & Sex & Fate \\
\hline 1 & 1988 & 835 & 1 & $\mathrm{~F}$ & Left hemiplegia & Mild & 780 & 2 & $\mathrm{~F}$ & Neonatal death & 820 & 3 & $\mathrm{~F}$ & Live born \\
\hline 2 & 1985 & 1100 & 3 & $M$ & Diplegia L > R & Mild & 930 & 1 & $\mathrm{~F}$ & Live born & 1060 & 2 & $\mathbf{M}$ & Live born \\
\hline 3 & 1980 & 1230 & 3 & $M$ & Right hemiplegia/diplegia & Mild & 880 & 1 & $M$ & Live born & 20 & 2 & $M$ & Stillborn \\
\hline 4 & 1986 & 1355 & 3 & $\mathbf{M}$ & Diplegia $L>R$ & Mild & 1110 & 1 & $\mathrm{~F}$ & Live born & 995 & 2 & $\mathrm{~F}$ & Live born \\
\hline 5 & 1989 & 1655 & 3 & $\mathrm{~F}$ & Right hemiplegia & Moderate & 1610 & 1 & $M$ & Live born & 1135 & 2 & $\mathrm{M}$ & Live born \\
\hline 6 & 1981 & 2170 & 1 & $M$ & Left hemiplegia/diplegia & Moderate & 2650 & 2 & $\mathrm{M}$ & Live born & 1470 & 3 & $M$ & Stillborn \\
\hline
\end{tabular}

